\title{
Antithrombotic activity of flavonoids and polyphenols rich plant species
}

\author{
MIRZA BOJIĆ1,* \\ ŽELJAN MALEŠ² \\ ANDREA ANTOLIĆ \\ IVANA BABIĆ ${ }^{4}$ \\ MAJA TOMIČIĆ ${ }^{4}$ \\ ${ }^{1}$ University of Zagreb Faculty \\ of Pharmacy and Biochemistry \\ Department of Medicinal Chemistry \\ HR-10000 Zagreb, Croatia \\ ${ }^{2}$ University of Zagreb Faculty \\ of Pharmacy and Biochemistry \\ Department of Pharmaceutical Botany \\ HR-10000 Zagreb, Croatia \\ ${ }^{3}$ University of Zagreb Faculty of Science \\ PDS Biology, HR-10000 Zagreb, Croatia \\ ${ }^{4}$ Croatian Institute of Transfusion \\ Medicine, HR-10000 Zagreb, Croatia
}

Accepted July 1, 2019

Published online September 6, 2019

\begin{abstract}
Cardiovascular diseases represent one of the most notable health problems of the modern civilization. Stroke and heart attack often lead to lethal outcome; essential problem underneath being thrombus formation. Prophylactic approaches include acetylsalicylic acid and clopidogrel therapy on the level of primary hemostasis, i.e., primary clot formation. In the last five years, in the USA, health care expenses related to cardiovascular diseases have increased $50 \%$, to over 350 billion dollars. Thus, application of plant species and medicinal plants rich in polyphenols in prevention of thrombus formation are of interest. This is supported by the fact that the number of publications on antiaggregatory effect of polyphenols has doubled in the last decade. In this review we focus on antiaggregatory effect of most abundant polyphenols - flavonoids, the effect of plant extracts rich in polyphenols (propolis, species Salvia sp., Calamintha nepeta L., Lavandula angustifolia Mill., Melissa officinalis L, Mentha x piperita L., Ocimum basilicum L., Origanum vulgare L., Rosmarinus officinalis L.) on platelet aggregation, association of chemical composition and antioxidant properties with the observed biological effect, and possible clinical significance of the published results.
\end{abstract}

Keywords: platelet aggregation, polyphenols, plant species, cardiovascular diseases

\section{INTRODUCTION}

Every year the American Heart Association publishes an update on heart disease and stroke statistics (1). Numbers from this report are overwhelming; cardiovascular diseases are underlying cause of death of over 840 thousand people in the USA, i.e., death of every third person. This represents a significant burden to health care system generating over 351.2 billion US dollars of direct costs, loss of productivity and mortality. As total direct medical costs of cardiovascular diseases are projected to increase to 749 billion US dollars in 2035 (1), prevention and supportive therapy are of interest.

\footnotetext{
*Correspondence; e-mail: mbojic@pharma.hr
} 
In 2016, coronary heart diseases were accounted for $43 \%$ of deaths followed by stroke $(17 \%)$, high blood pressure (10\%), heart failure $(9 \%)$, diseases of the arteries $(3 \%)$, and other cardiovascular diseases (1-3). Underlying cause, in some cases can be attributed to the formation of thrombus, a blood clot that can obstruct blood vessels and cause stroke or heart attack. In case of acute myocardial infarction, acetylsalicylic acid is indicated to over $98 \%$ of patients in doses up to $100 \mathrm{mg}$ daily to prevent platelet aggregation, i.e., clinical manifestation of atherosclerosis $(1,4)$. While acetylsalicylic acid acts on cyclooxygenase 1 preventing generation of thromboxane $\mathrm{A}_{2}$, a strong inducer of platelet aggregation, clopidogrel represents another antiplatelet drug of choice acting as antagonist of adenosine diphosphate (ADP), a weak inducer of platelet aggregation (5). However, these drugs do not come without side effects; acetylsalicylic acid hydrolyses to salicylic acid that causes gastrointestinal adverse effects, and clopidogrel can cause thrombotic thrombocytopenic purpura (6).

Flavonoids represent a diverse class of compounds found in higher plants, including vegetables and fruits, well known due to their antioxidant properties. Albert Szent-Györgyi, a Nobel laureate known for his work on vitamin C, discovered flavonoids and classified them as vitamins: bioflavonoids of vitamin P (7). Flavonoids have core chromone skeleton to which phenyl is bound at a position 2 (flavonoids) or 3 (isoflavonoids) (Fig. 1). Classification is based on the structure of ring $\mathrm{C}$, while diversity comes from hydroxylation and subsequent methylation and glycosidation of hydroxyl groups. There are over 4.000 possible flavonoids, and many of them have been subject to research due to their beneficial effects in vitro (antibacterial, antiviral, antifungal, hepatoprotective, immunomodulating, etc.) (8).

As we have been evolutionary exposed to flavonoids through diet, humans have developed mechanism how to deal with these xenobiotics. Flavonoids similarly to vitamins are stipulated as safe substances in doses not superseding recommended daily intakes. Consequently, flavonoids are subject of research as dietary supplements as well as lead compounds in drug design.

One of the positive effects that has been of interest is antiplatelet activity of flavonoids, i.e., prevention of primary clot formation by inhibiting platelet aggregation. While antiaggregatory effect of flavonoids was of interest in the $20^{\text {th }}$ century, in vitro concentrations to observe the effect were extremely high (100 fold greater than concentration of flavonoids achieved in vivo). In 1998, Janssen et al. (9) concluded that "the antiaggregatory effects of

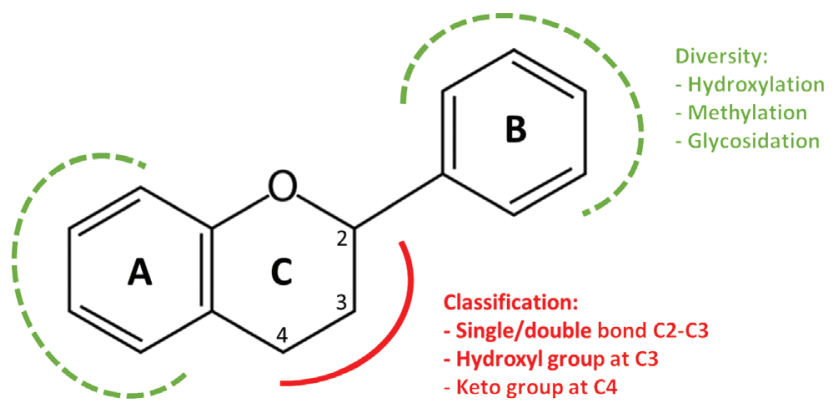

Fig. 1. Structural features of flavonoids. Flavonoids are classified based on the structural features of the ring C. Diversity comes from the hydroxylations, and subsequent methylations or glycosidations. 
flavonoids seen in vitro are due to concentrations that cannot be attained in vivo". Moreover, they added "effects of dietary flavonols and flavones on cardiovascular risk are possibly not mediated by hemostatic variables" (9).

Antiplatelet activity of flavonoids was revisited a decade later, as methodology of platelet aggregation analysis was improved. Although optical aggregometry represents golden standard for platelet function analysis, impedance aggregometry was developed enabling analysis on whole blood and making a step closer to biological system, i.e., tissue (10).

In this review we focus on antiaggregatory effect of most abundant polyphenols flavonoids, the effect of plant extracts rich in polyphenols on platelet aggregation, association of chemical composition and antioxidant properties with the observed biological effect, and possible clinical significance of the published results.

\section{EXPERIMENTAL DETERMINATION OF PLATELET AGGREGATION AND RESULTS EXPRESSION}

Many studies of flavonoids effect on platelet aggregation do not incorporate differences between individuals. Quite often studies were performed by optical aggregometry using platelet rich plasma of one individual (11). Having in mind that the normal range varies up to $4-5$ folds between lower and upper limits, the effect of interindividual differences was undermined.

Results are usually expressed as inhibitory concentration that reduces aggregation by $50 \%\left(I C_{50}\right)$. Although most often used, $I C_{50}$ is far from ideal value for expressing results as it is highly dependent on experimental set up, consequently it requires positive control to be able to compare results to other studies. When our group started research on flavonoids antiaggregatory activity, our main concern was to include inter individual differences within the algorithm for determination of minimal concentration of flavonoid or plant extract that causes statistically significant reduction of platelet aggregation (Fig. 2). Platelet aggregation follows normal distribution enabling the use of Student's $t$-test for the assessment of significance. Minimal number of blood samples needed is three (12). In principle, minimal antiaggregatory concentration $(\mathrm{MINaAC})$ determination does not require the use of positive control.

Protocol that was used was generic procedure used for analysis of controls, e.g., acetylsalicylic acid in platelet aggregation assay induced by arachidonic acid: $300 \mu \mathrm{L}$ of blood is diluted with $300 \mu \mathrm{L}$ of physiological solution, $20 \mu \mathrm{L}$ of inhibitor are added, and reaction is started by introducing agonist of aggregation (13). Commercially available inducers include ADP, thrombin receptor-activating peptide (hexapeptide, TRAP-6), collagen, arachidonic acid, ristocetine. The advantage of using different agonists of aggregation is assessment of different signaling pathways that are inhibited.

Quite often concentrations of extract are arbitrarily used in the studies, e.g., grape (Vitis vinifera L.) seed extracts reduced platelet aggregation in the test induced by ADP in relatively high concentrations of 7.5 and $15 \mathrm{~g} \mathrm{~L}^{-1}$, equivalent of 25 and $50 \mathrm{mmol} \mathrm{L}^{-1}$ if recalculated to molarity based on quercetin molar mass $\left(302.24 \mathrm{~g} \mathrm{~mol}^{-1}\right)(14)$.

Other issue is that quite often results of platelet aggregation assays are not related to the chemical composition of the extract. Walnut (Juglans regia L.) hull extract showed antiplatelet activity at the concentration of $25 \mathrm{mg} \mathrm{L}^{-1}\left(8.2 \mu \mathrm{mol} \mathrm{L}^{-1}\right.$ of quercetin equivalent) in 


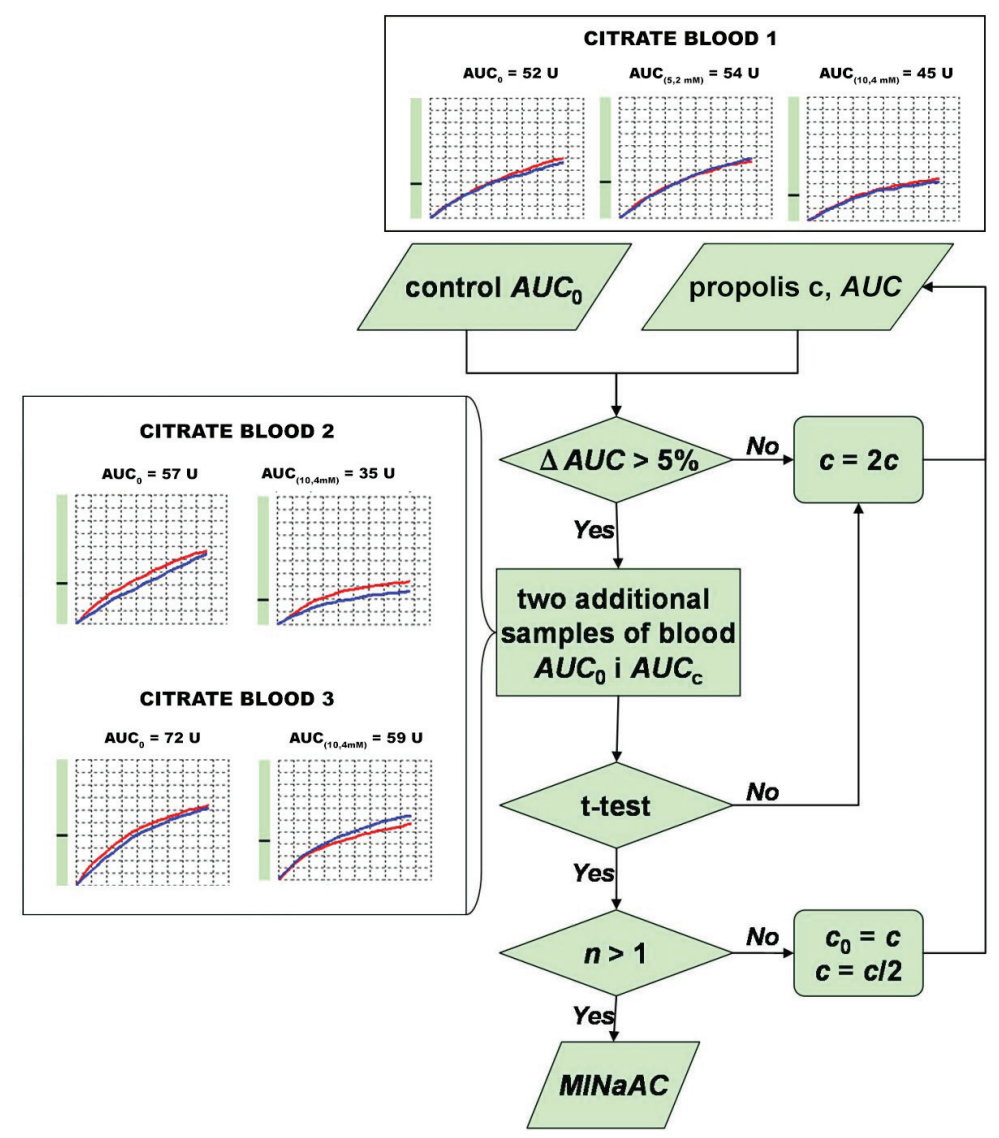

Fig. 2. Determination of minimal antiaggregatory concentration (MINaAC) of propolis. Result of platelet aggregation assay, that shows reduction in platelet aggregation measured as area under curve of more than $5 \%$ (extract tested $v$ s. solvent control), has to be confirmed with two additional citrate blood sampled of different donors. If analyzed concentration of extract shows statistically significant difference (tested by Student's $t$-test), this concentration is regarded MINaAC. Original figure describing methodology of $M I N a A C$ determination for prunetin was published in ref. 11 (C) Bojić et al.; licensee BioMed Central Ltd. 2011).

platelet aggregation assay induced by thrombin (15). This was presumed to be due to polyphenolic composition of the extract. However, no statistical analysis was conducted to support this claim.

\section{THE EFFECT OF FLAVONOIDS AND PLANT EXTRACTS ON PLATELET AGGREGATION}

ADP is a weak agonist of platelet aggregation, and is secreted from platelets upon activation by any other inducer of aggregation. Thus, even a weak inhibitor of platelet aggregation should be detected in this platelet aggregation test induced by ADP. Analysis 
of a set of 30 flavonoid aglycones showed that all tested flavonoids exhibit inhibitory effect on platelet aggregation in the range of $0.12 \mu \mathrm{mol} \mathrm{L}^{-1}$ (3,6-dihydroxyflavone, syringetin) to $122 \mu \mathrm{mol} \mathrm{L}^{-1}$ (galangin, fisetin) (12).

Structure-activity relationship analysis showed that antiaggregatory activity of flavonoids is highly dependent of the C-ring structure that determines the class of compounds. If double bond is present between C2 and C3 it increases antiaggregatory activity of flavonoids in case of non-methylated flavonoids. Most active flavonoids possess hydroxyl group at the position 6. Methylation of rings A and B decreases antiplatelet activity. Catechins are the most potent class of flavonoids, while isoflavonoids exert the lowest antiplatelet activity (12).

Although our group was mainly focused on flavonoid aglycons, antiaggregatory effect was observed with flavonoid glycosides as well. Scolymoside, i.e., luteolin-7-O-rutinoside showed antiaggregatory effect at the concentration of $5 \mu \mathrm{mol} \mathrm{L}^{-1}$ in the platelet aggregation assay induced by thrombin, while its aglycon luteolin showed similar results in platelet aggregation assay induced by $\mathrm{ADP}(\mathrm{MINaAC}=7.6 \mu \mathrm{mol} \mathrm{L}-1)(16)$. Wogonin, a flavone isolated from Scutellaria baicalensis Georgi, showed in its glycoside form, wogonin-7-O-glucuronide, antiaggregatory effect at $5 \mu \mathrm{mol} \mathrm{L} \mathrm{L}^{-1}$ in platelet aggregation test induced by thrombin (17). Vicenin-2, a C-glycoside present in Cyclopia subternata Vogel, showed antiaggregatory activity in platelet aggregation assay induced by thrombin at concentration of $5 \mu \mathrm{mol} \mathrm{L}^{-1}$ (18).

Mechanisms of antiplatelet action of individual flavonoids have been studied and include: change of bilayer function, change in ROS concentrations and oxidative stress,

Table I. Possible mechanism of antiplatelet activity of individual flavonoids

\begin{tabular}{lll}
\hline Mechanism of action & Influence on platelet aggregation & Reference \\
\hline Change of bilayer function & $\downarrow$ quercetin, naringenin, hesperetin & 19 \\
\hline & $\downarrow$ epicatechin & 20,21 \\
& $\downarrow$ hesperetin & 22 \\
Oxidative stress & $\leftrightarrow$ hesperetin & 23 \\
& $\uparrow$ hesperetin (via xanthine oxidoreductase) & 24 \\
& $\uparrow$ baicalein, morin, myricetin, quercetin, rutin & 25 \\
\hline Intracellular Ca ${ }^{2+}$ concentration & $\downarrow$ hesperetin & 22,26 \\
\hline Inhibition of phospholipase C & $\downarrow 3,6$-dihydroxyflavone & 27 \\
\hline \multirow{2}{*}{ Inhibition of cAMP phosphodiesterase } & $\uparrow$ isorhamnetin, isosakuranetin & 22 \\
\hline Inhibition of cyclooxygenase & $\downarrow$ quercetin, apigenin, catechin, tamarixetin & 28,29 \\
\hline Inhibition of thromboxane A ${ }_{2}$ synthase & $\downarrow$ epicatechin & 30 \\
\hline
\end{tabular}

Influence on platelet aggregation: $\downarrow$ decrease, $\leftrightarrow$ no influence, $\uparrow$ increase 
change of intracellular $\mathrm{Ca}^{2+}$ concentration, inhibition of enzymes (phospholipase $\mathrm{C}$, cAMP phosphodiesterase, cyclooxygenase, thromboxane $\mathrm{A}_{2}$ synthase) (19-33) (Table I). As all flavonoids showed antiplatelet activity in platelet aggregation assay induced by ADP, a common, non-specific mechanism of action was assumed rather than focusing on individual flavonoid mode of action, through one of the aforementioned mechanisms. Most flavonoids are highly lipophilic and stabilization of platelet membrane could be common mode of action explaining why all of the flavonoids possess antiaggregatory effect in ADP induced platelet aggregation assay. MINaAC values were related to lipophilicity (computed $\log$ arithm of partition coefficient, $(\log P)$ showing strong negative correlation $R=$ $-0.758(p=0.007)$ for flavones and moderate negative correlation $R=-0.592(p=0.020)$ for combined groups of flavones and flavanones (34). Also, all-methylated counterpart of flavonoid aglycons have greater antiaggregatory potential as shown on pentamethylquercetin (35). Pentamethylquercetin is more lipophilic in comparison to quercetin (ClogP 3.2 vs. 1.5 respectively), and it shows antiaggregatory activity in assays of platelet aggregation induced by ADP, collagen and thrombin at the concentration of $10 \mu \mathrm{mol} \mathrm{L}-1$ (MINaAC of quercetin is $\left.15 \mu \mathrm{mol} \mathrm{L}^{-1}\right)(12,35)$.

Further experiments showed that most potent flavonoid found in our library is flavanone. As lipophilicity is related to antiplatelet activity our assumption was that flavonoids inhibit platelet aggregation by stabilizing platelet membrane, a key point of platelet aggregation. When activated, platelets expose increased number of receptors at cell surface. If flavonoids stabilize the membrane, number of exposed receptors should decrease. This was confirmed by flow cytometry, in which $488 \mu \mathrm{mol} \mathrm{L}^{-1}$ flavanone inhibited inside-out expression of integrin $\alpha \operatorname{IIb} \beta 3$ by cca. $40 \%$ in a platelet aggregation assay induced by TRAP-6 (34).

While antiaggregatory effect of flavonoids is well described in the literature, proaggregatory activity of flavonoids was first reported by our group (11). Polyhydroxylated flavonoids in the platelet assay induced by arachidonic acid induced platelet aggregation. As flavonoids act as antioxidants, they stimulate peroxide activity of prostaglandin $\mathrm{H}$ synthase, i.e., biotransformation of prostaglandin $\mathrm{G}_{2}$ to prostaglandin $\mathrm{H}_{2}$. Prostaglandin $\mathrm{H}_{2}$ is further converted to thromboxane $\mathrm{A}_{2}$ (by thromboxane $\mathrm{A}_{2}$ synthase), and both of these eicosanoids stimulates platelet aggregation.

In the last decade, influence of plants on platelet aggregation has been increasingly studied. Plant extracts represent complex mixtures that requires chemical characterization. Even with extensive analysis of composition, it is not always easy to pin point constituents responsible for the observed effect. Three cases in which antiplatelet activity of plant extracts was related to either one compound, several compounds or antioxidant capacity are discussed.

Melissa officinalis L. is a shrub plant that has characteristic smell of lemon justifying its English name lemon balm. Major constituents of lemon balm leaves extracts are flavonoids and phenolic acids. While effect of lemon balm extracts on platelet aggregation induced by $\mathrm{ADP}$ is relatively small, i.e., up to $18 \%$ reduction of platelet aggregation, it is statistically significant and can be related to the content of rosmarinic acid (36). Dihydroxymyricetin-3-O- $\alpha$-rhamnoside was found to be one of the major phenolic constituents responsible for antiaggregatory effect of Licania cruegeriana Urb. extracts (37). This compound has shown inhibition of platelet aggregation in assays induced by collagen, arachidonic acid and ADP. Isoquercitrin and hyperin were related to the antiplatelet activity of Apocynum venetum L. (38). These compounds showed statistically significant inhibition of platelet aggregation induced by ADP in concentrations $10 \mathrm{mg} \mathrm{L}^{-1}$ hyperin $(21.5 \mu \mathrm{mol} \mathrm{L}-1)$ and $50 \mathrm{mg} \mathrm{L}^{-1}$ isoquercitrin 
(107.7 $\left.\mu \mathrm{mol} \mathrm{L}{ }^{-1}\right)$. However, these results were obtained on one plant extract sample. Onion (Allium cepa L.) peel extract showed antiplatelet activity in platelet aggregation assay induced by collagen at the concentration of $50 \mathrm{mg} \mathrm{L}^{-1}\left(0.17 \mu \mathrm{mol} \mathrm{L}^{-1}\right.$ of quercetin equivalent) that was mainly attributed to quercetin (39).

Salvia officinalis L. and Salvia brachyodon Vand. leaves extracts showed antiplatelet activity in concentrations of $21 \mathrm{nmol} \mathrm{L}^{-1}(40)$. Analysis of constituents did not show relation with neither flavonoid nor polyphenolic acids content. However, inhibition of platelet aggregation was related to antioxidant activity determined using stable free radical DPPH $(R=0.701, p=0.035)$. This suggests that antiplatelet activity is more complexly related to antioxidant properties of more constituents, rather than individual compound. Sage extracts are extremely potent, and require further studies. Extracts of yuzu (Citrus junos Sieb ex Tanaka), hallabong $((C$. unshiu Marcov $\times$ C. sinensis Osbeck $) \times C$. reticulata Blanco $)$ and orange (C. sinensis Osbeck) have shown platelet aggregation reduction using methanol, ethyl acetate or hexane as extraction solvent (41). At the concentration of $1 \mathrm{~g} \mathrm{~L}^{-1}$ all ethyl acetate extracts showed nearly complete inhibition of platelet aggregation in the test induced by collagen, with reduction of platelet aggregation comparable to the $1.7 \mathrm{mmol} \mathrm{L}^{-1}$ acetylsalicylic acid. It should be noted that arachidonic acid would be more appropriate inducer if comparison with acetylsalicylic acid was the objective. Nevertheless, this study showed that inhibition of platelet aggregation is related to the content of the total polyphenols $(R=0.654, p<0.05)$ and antioxidant activity of extracts determined by copper ion-reducing power $(R=0.654, p<0.05)$.

Propolis represents a rich source of polyphenols. We were the first group to report antiplatelet effect of propolis extracts (42). To determine the content of polyphenols HPLC coupled with diode array detection was used; flavonoids ranged between 7 and $55 \mathrm{mg} \mathrm{g}^{-1}$ and phenolic acids 0.8 to $4.5 \mathrm{mg} \mathrm{g}^{-1}$. MINaAC ranged from $5 \mu \mathrm{mol} \mathrm{L}^{-1}$ to $10.4 \mathrm{mmol} \mathrm{L}^{-1}$. In this case it was determined that antiplatelet activity of propolis can be related to some extend to the content of luteolin and pinocembrin-7-methyleter, i.e., the lower the content of luteolin and higher the content of pinocembrin-7-methyleter are, the higher antiplatelet activity is. Peel extract of Campomanesia adamantium (Cambess.) O. Berg showed antiaggregatory effect in platelet aggregation assay induced by arachidonic acid at $2.5 \mathrm{~g} \mathrm{~L}^{-1} \mathrm{con}-$ centration ( $8.2 \mathrm{mmol} \mathrm{L}^{-1}$ of quercetin equivalent) (43). This was attributed to quercetin and myricetin. Angelica shikokiana Makino ex Y. Yabe, herbal extracts showed reduction in platelet aggregation at all analyzed concentrations $\left(1 \mathrm{mg} \mathrm{L}^{-1}\right.$ being the lowest, i.e., $3.3 \mu \mathrm{mol} \mathrm{L}{ }^{-1}$ of quercetin equivalent) in platelet aggregation assays induced by ADP and arachidonic acid (44). This was attributed to polyphenols that were detected in the extract and individually tested in the same platelet assays. Interestingly, authors found that glycosides had lower antiplatelet potential when compared to their aglycons.

Other plant extracts that have shown antiplatelet activity are: Calamintha nepeta L., Lavandula angustifolia Mill., Mentha x piperita L., Ocimum basilicum L., Origanum vulgare L., and Rosmarinus officinalis L. Constituents of these extracts are mainly phenolic compounds (Table II). As these analyses were performed on one sample of plant extract, further studies of greater number of samples collected from different locations and in different collection years, are needed to undoubtedly determine constituents responsible for the observed antiplatelet activity.

Scutia buxifolia Reissek was analyzed in platelet aggregation assays as an aqueous lyophilized extract. Leaves extracts were less potent when compared to stem bark. Stem bark extracts showed antiaggregatory effect in platelet aggregation assay induced by ADP 
Table II. Antiplatelet activity of plant extracts of Lamiaceae species and major constituents determined by HPLC-MS-ESI-TOF analysis ${ }^{a}$

\begin{tabular}{|c|c|c|}
\hline Sample & $\begin{array}{l}\text { MINaAC } \\
\left(\mathrm{mg} \mathrm{L}^{-1}\right)\end{array}$ & Identified constituents $^{b}$ \\
\hline $\begin{array}{l}\text { Calamintha } \\
\text { nepeta } \mathrm{L} \text {. }\end{array}$ & 2.0 & $\begin{array}{l}\text { Caffeic acid (180.0422), rosmarinic acid (360.0842), umbelliferone } \\
(162.0314)\end{array}$ \\
\hline $\begin{array}{l}\text { Lavandula } \\
\text { angustifolia L. }\end{array}$ & 2.0 & $\begin{array}{l}\text { Apigenin (270.0528), carnosic acid (300.2089), carnosol (330.1833), caffeic } \\
\text { acid (180.0422), chrysmaritine (314.0793), umbelliferone (162.0314) }\end{array}$ \\
\hline $\begin{array}{l}\text { Mentha } x \\
\text { piperita L. }\end{array}$ & 20 & $\begin{array}{l}\text { Eriodictyol (288.0634), carnosic acid (300.2089), caffeic acid (180.0422), } \\
\text { kaempferol (180.1149), chrysmaritine (314.0793), luteoline (286.0477), } \\
\text { rosmarinic acid (360.0842), salvigenin (328.0949), umbelliferone (162.0314) }\end{array}$ \\
\hline $\begin{array}{l}\text { Ocimum } \\
\text { basilicum L. }\end{array}$ & 0.2 & Caffeic acid (180.0422), umbelliferone (162.0314) \\
\hline $\begin{array}{l}\text { Origanum } \\
\text { vulgare L. }\end{array}$ & 2.0 & Caffeic acid (180.0422), salvigenin (328.0949), umbelliferone (162.0314) \\
\hline $\begin{array}{l}\text { Rosmarinus } \\
\text { officinalis L. }\end{array}$ & 2.0 & $\begin{array}{l}\text { Acacetine (284.0687), apigenin (270.0528), diosmetin (300.0636), epiros- } \\
\text { manol (346.1779), epirosmanol methylether (360.1937), carnosol } \\
\text { (330.1833), caffeic acid (180.0422), chrysmaritine (314.0793), rosmanol } \\
\text { (346.178), salvigenin (328.0949), umbelliferone (162.0314) }\end{array}$ \\
\hline
\end{tabular}

${ }^{a}$ Boijć et al., unpublished data.

${ }^{\mathrm{b}}$ Each compound is identified based on high resolution molecular mass stated in brackets.

at the minimal concentration of $50 \mathrm{mg} \mathrm{L}^{-1}\left(0.17 \mu \mathrm{mol} \mathrm{L}^{-1}\right.$ of quercetin equivalent) (45). Vitis labrusca L. (fox grape) leaves extract was analyzed in platelet aggregation assays induced by collagen, thrombin and ADP showing statistically significant inhibition of platelet aggregation at the concentration of $1 \mathrm{~g} \mathrm{~L}^{-1}\left(3.3 \mathrm{mmol} \mathrm{L}^{-1}\right.$ of quercetin equivalent) in ex vivo experiments irrespectively of the platelet aggregation agonist used (46). Ex vivo experiments on blood of male rats after consumption of fox grape leaves extract (100 mg per $\mathrm{g}$ of animal mass) showed lowered platelet aggregation in platelet aggregation assays induced by ADP. Extract of Lagenaria siceraria (Molina) Standl. fruits showed antiplatelet activity with $I C_{50}$ value of $15.8 \mathrm{~g} \mathrm{~L}^{-1}$ concentration ( $52 \mathrm{mmol} \mathrm{L}^{-1}$ of quercetin equivalent) in platelet aggregation assay induced by ADP (47). This was attributed to flavonoids content. Extract of Arnica montana L. flowers showed reduction of platelet aggregation assay induced by ADP at the concentration of $7.5 \mathrm{mg} \mathrm{L}^{-1}(25 \mu \mathrm{mol} \mathrm{L}-1$ of quercetin equivalent) (48). However, no reduction of platelet aggregation was observed in collagen and arachidonic acid induced platelet aggregation assays.

\section{CLINICAL SIGNIFICANCE OF THE EFFECT OF POLYPHENOLS ON PLATELET AGGREGATION}

Epidemiological and clinical studies on the influence of flavonoids on cardiovascular diseases are rare and inconsistent. The major problem presents evolutional exposition to flavonoids through diet, and developed mechanisms that reduce their bioavailability (transporters that reduce absorption and metabolism that increases excretion from the 
body). Although studies on European population show consumption of flavonoids of more than $100 \mathrm{mg}$ per day (49), bioavailability of flavonoids is limited up to $24 \%$ as reported for quercetin (50). As half-life of quercetin in plasma is 11 to 28 hours, it is regarded that slow elimination increases accumulation of quercetin in body (51). Concentration in plasma is usually reported of up to $1 \mu \mathrm{mol} \mathrm{L} \mathrm{L}^{-1}$ (52). Our group has concluded that flavonoids can cause clinically significant interaction in platelet aggregation assay induced by ristocetin and arachidonic acid. Even low concentrations of flavonoids (i.e., $60 \mathrm{nmol} \mathrm{L}^{-1}$ ) can influence platelet aggregation assays induced by arachidonic acid and ristocetin (11). These assays are used for the assessment of von Willebrand factor (vWF) function, and flavonoids can consequently cause misdiagnosis of blood clot disorders related to vWF.

In clinical study on healthy males, influence of tomato (Solanum lycopersicum L.) pomace extract was tested ex vivo (53). It showed reduction of platelet aggregation in the test induced by ADP ( 5 days after starting the treatment, 3 hours after last dose was consumed). While polyphenol profile of tomato extract was analyzed by high performance liquid chromatography coupled with mass spectrometry (HPLC-MS), no clear indication of component(s) responsible for the activity was provided. Polyphenols enriched beverage (326 mg L $\mathrm{m}^{-1}$ of gallic acid equivalent) reduced platelet aggregation in healthy athletes after stress (marathon) (54). Anthocyanin consumption (320 mg per day) by healthy volunteers reduced ex vivo platelet aggregation by $29 \%$ in platelet aggregation assay induced by ADP (55).

Nearly every epidemiological study of the flavonoids' influence on cardiovascular diseases is inconclusive and seeks further studies (56). However, one of the rare studies confirming beneficial effects of flavonoids in cardiovascular diseases was one performed by Wang et al. (57). Meta-analysis of published data from 1966 to 2013 shows that increase of flavanol intake by $20 \mathrm{mg}$ per day reduces risk of stroke by $14 \%$ in men. Same effect was not confirmed in females.

\section{CONCLUSIONS}

Flavonoids influence platelet aggregation in concentrations that can be achieved in vivo. Some flavonoids, e.g., flavon, can influence platelet aggregation in nanomolar concentration and consequently impair interpretation of functional tests of primary hemostasis. Common non-specific mechanism could be related to stabilization of platelet membrane based on strong negative correlation of platelet aggregation (MINaAC) and lipophilicity $(C \log P)$, and flow cytometry experiments showing reduction of exposed receptors on platelet surface after treatment with flavanone. Plants rich in polyphenols present interesting area of research as some extracts show antiaggregatory effect in nanomolar range $(O$. basilicum, S. brachyodon, S. officinalis).

One question that was asked at the conference at which this work was presented, does this mean consumption of flavonoids should be promoted in prevention of cardiovascular diseases? Answer is not unanimous, as clinical and epidemiological studies are insufficient. Flavonoids were discovered as vitamins, having a role of antioxidants in oxidative stress that is responsible for many diseases of modern civilization (cancer, cardiovascular diseases, neurodegenerative diseases, etc.). As in the case with many vitamins, there is no clear evidence supporting consumption of vitamins other than in cases of hypovitaminosis. However, one multi-vitamin tablet a day is encouraged based on the fact that this supports physiologic processes in which vitamins are involved. 


\section{REFERENCES}

1. E. J. Benjamin, P. Muntner, A. Alonso, M. S. Bittencourt, C. W. Callaway, A. P. Carson, A. M. Chamberlain, A. R. Chang, S. Cheng, S. R. Das, F. N. Delling, L. Djousse, M. S. V. Elkind, J. F. Ferguson, M. Fornage, L. C. Jordan, S. S. Khan, B. M. Kissela, K. L. Knutson, T. W. Kwan, D. T. Lackland, T. T. Lewis, J. H. Lichtman, C. T. Longenecker, M. S. Loop, P. L. Lutsey, S. S. Martin, K. Matsushita, A. E. Moran, M. E. Mussolino, M. O'Flaherty, A. Pandey, A. M. Perak, W. D. Rosamond, G. A. Roth, U. K. A. Sampson, G. M. Satou, E. B. Schroeder, S. H. Shah, N. L. Spartano, A. Stokes, D. L. Tirschwell, C. W. Tsao, M. P. Turakhia, L. B. VanWagner, J. T. Wilkins, S. S. Wong and S. S. Virani, Heart disease and stroke statistics-2019 update: A report from the American Heart Association, Circulation 139 (2019) e56-e528; https://doi.org/10.1161/cir.00000000000000659

2. M. J. Budoff, S. Achenbach, R. S. Blumenthal, J. J. Carr, J. G. Goldin, P. Greenland, A. D. Guerci, J. A. Lima, D. J. Rader, G. D. Rubin, L. J. Shaw and S. E. Wiegers, Assessment of coronary artery disease by cardiac computed tomography: a scientific statement from the American Heart Association Committee on Cardiovascular Imaging and Intervention, Council on Cardiovascular Radiology and Intervention, and Committee on Cardiac Imaging, Council on Clinical Cardiology, Circulation 114 (2006) 1761-1791; https://doi.org/10.1161/circulationaha.106.178458

3. P. Greenland, J. S. Alpert, G. A. Beller, E. J. Benjamin, M. J. Budoff, Z. A. Fayad, E. Foster, M. A. Hlatky, J. M. Hodgson, F. G. Kushner, M. S. Lauer, L. J. Shaw, S. C. Smith, A. J. Taylor, W. S. Weintraub and N. K. Wenger, $2010 \mathrm{ACCF} / \mathrm{AHA}$ guideline for assessment of cardiovascular risk in asymptomatic adults: a report of the American College of Cardiology Foundation/American Heart Association Task Force on Practice Guidelines, Circulation 122 (2010) e584-e636; https://doi.org/10.1161/ cir.0b013e3182051b4c

4. D. L. Bhatt, Can clopidogrel and aspirin lower mortality in patients with acute myocardial infarction? Nat. Clin. Pract. Cardiovasc. Med. 3 (2006) 182-183; https://doi.org/10.1038/ncpcardio0508

5. J. Sullivan and N. Amarshi, Dual antiplatelet therapy with clopidogrel and aspirin, Am. J. Health Syst. Pharm. 65 (2008) 1134-1143; https://doi.org/10.2146/ajhp060662

6. A. Algra and J. van Gijn, Is clopidogrel superior to aspirin in secondary prevention of vascular disease? Curr. Control Trials Cardiovasc. Med. 1 (2000) 143-145; https://doi.org/10.1186/cvm-1-3-143

7. A. Grzybowski and K. Pietrzak, Albert Szent-Györgyi (1893-1986): the scientist who discovered vitamin C, Clin. Dermatol. 31 (2013) 327-331; https://doi.org/10.1016/j.clindermatol.2012.08.001

8. B. Havsteen, Flavonoids, a class of natural products of high pharmacological potency, Biochem. Pharmacol. 32 (1983) 1141-1148; https://doi.org/10.1016/S0163-7258(02)00298-X

9. K. Janssen, R. P. Mensink, F. J. Cox, J. L. Harryvan, R. Hovenier, P. C. Hollman and M. B. Katan, Effects of the flavonoids quercetin and apigenin on hemostasis in healthy volunteers: results from an in vitro and a dietary supplement study, Am. J. Clin. Nutr. 67 (1998) 255-262; https://doi.org/10.1093/ ajcn/67.2.255

10. U. T. Seyfert, H. Haubelt, A. Vogt and P. Hellstern, Variables influencing Multiplate whole blood impedance platelet aggregometry and turbidimetric platelet aggregation in healthy individuals, Platelets 18 (2007) 199-206. https://doi.org/10.1080/09537100600944277

11. M. Bojić, Ž. Debeljak, M. Medić-Šarić and M. Tomičić, Interference of selected flavonoid aglycons in platelet aggregation assay, Clin. Chem. Lab. Med. 50 (2012) 1403-1408; https://doi.org/10.1515/cclm2011-0960

12. M. Bojić, Ž. Debeljak, M. Tomičić, M. Medić-Šarić and S. Tomić, Evaluation of antiaggregatory activity of flavonoid aglycone series, Nutr. J. 10 (2011) Article ID 73 (8 pages); https://doi.org/10.1186/14752891-10-73

13. A. Calatzis, R. M. Loreth and M. Spannagl, Multiplate ${ }^{\circledast}$ Platelet Function Analysis - Application and Interpretation, Dynabyte $\mathrm{GmbH}$, Munich 2006. 
14. M. Bijak, A. Sut, A. Kosiorek, J. Saluk-Bijak and J. Golanski J, Dual anticoagulant/antiplatelet activity of polyphenolic grape seeds extract, Nutrients 11 (2019) Article ID 93 (9 pages); https://doi. org/10.3390/nu11010093

15. A. Meshkini and M. Tahmasbi, Antiplatelet aggregation activity of walnut hull extract via suppression of reactive oxygen species generation and caspase activation, J. Acupunct. Meridian Stud. 10 (2017) 193-203; https://doi.org/10.1016/j.jams.2017.02.007

16. E. K. Yoon, S. K. Ku, W. Lee, S. Kwak, H. Kang, B. Jung and S. Bae, Antitcoagulant and antiplatelet activities of scolymoside, BMB Rep. 48 (2015) 577-582; https://doi.org/10.5483/BMBRep.2015.48.10.044

17. S. K. Ku and J. S. Bae, Antithrombotic activities of wogonin and wogonoside via inhibiting platelet aggregation, Fitoterapia 98 (2014) 27-35; https://doi.org/10.1016/j.fitote.2014.07.006

18. W. Lee W and J. S. Bae, Antithrombotic and antiplatelet activities of vicenin-2, Blood Coagul. Fibrinolysis 26 (2015) 628-634; https://doi.org/10.1097/MBC.00000000000000320

19. A. Saija, M. Scalese, M. Lanza, D. Marzullo, F. Bonina and F. Castelli, Flavonoids as antioxidant agents: importance of their interaction with biomembranes, Free Radic. Biol. Med. 19 (1995) 481-486; https://doi.org/10.1016/0891-5849(94)00240-K

20. A. Polette, D. Lemaitre, M. Lagarde and E. Véricel, n-3 fatty acid-induced lipid peroxidation in human platelets is prevented by catechins, Thromb. Haemost. 75 (1996) 945-949; https://doi. org/10.1055/s-0038-1650399

21. T. J. Neiva, L. Morais, M. Polack, C. M. Simões and E. A. D'Amico, Effects of catechins on human blood platelet aggregation and lipid peroxidation, Phytother. Res. 13 (1999) 597-600; https://doi. org/10.1002/(SICI)1099-1573(199911)13:7<597::AID-PTR512>3.0.CO;2-Z

22. S. L. Hwang and G. C. Yen, Modulation of Akt, JNK, and p38 activation is involved in citrus flavonoid-mediated cytoprotection of PC12 cells challenged by hydrogen peroxide, J. Agric. Food. Chem. 57 (2009) 2576-2582; https://doi.org/10.1021/jf8033607

23. F. Orallo, E. Alvarez, H. Basaran and C. Lugnier, Comparative study of the vasorelaxant activity, superoxide-scavenging ability and cyclic nucleotide phosphodiesterase-inhibitory effects of hesperetin and hesperidin, Naunyn. Schmiedebergs Arch. Pharmacol. 370 (2004) 452-463; https://doi. org/10.1007/s00210-004-0994-6

24. T. P. Dew, A. J. Day and M. R. Morgan, Xanthine oxidase activity in vitro: effects of food extracts and components, J. Agric. Food Chem. 53 (2005) 6510-6515; https://doi.org/10.1021/jf050716j

25. D. S. Chou, J. J. Lee, G. Hsiao, C. Y. Hsieh, Y. J. Tsai, T. F. Chen and J. R. Sheu, Baicalein induction of hydroxyl radical formation via 12-lipoxygenase in human platelets: an ESR study, J. Agric. Food Chem. 55 (2007) 649-655; https://doi.org/10.1021/jf062584f

26. Y. R. Jin, X. H. Han, Y. H. Zhang, J. J. Lee, Y. Lim, J. H. Chung and Y. P. Yun, Antiplatelet activity of hesperetin, a bioflavonoid, is mainly mediated by inhibition of PLC-gamma2 phosphorylation and cyclooxygenase-1 activity, Atherosclerosis 194 (2007) 144-152; https://doi.org/10.1016/j.atherosclerosis.2006.10.011

27. O. A. Ogunbayo, R. M. Harris, R. H. Waring, C. J. Kirk and F. Michelangeli, Inhibition of the sarcoplasmic/endoplasmic reticulum $\mathrm{Ca}^{2+}$-ATPase by flavonoids: a quantitative structure-activity relationship study, IUBMB Life 60 (2008) 853-858; https://doi.org/10.1002/iub.132

28. G. P. Hubbard, S. Wolffram, J. A. Lovegrove and J. M. Gibbins, Ingestion of quercetin inhibits platelet aggregation and essential components of the collagen-stimulated platelet activation pathway in humans, J. Thromb. Haemost. 2 (2004) 2138-2145. https://doi.org/10.1111/j.1538-7836.2004.01067.x

29. B. Wright, L. A. Moraes, C. F. Kemp, W. Mullen, A. Crozier, J. A. Lovegrove and J. M. Gibbins, A structural basis for the inhibition of collagen-stimulated platelet function by quercetin and structurally related flavonoids, Br. J. Pharmacol. 159 (2010) 1312-1325; https://doi.org/10.1111/j.1476-5381.2009.00632.x

30. L. Liu, D. M. Xu and Y. Y. Cheng, Distinct effects of naringenin and hesperetin on nitric oxide production from endothelial cells, J. Agric. Food Chem. 56 (2008) 824-829; https://doi.org/10.1021/jf0723007 
31. M. Dell'Agli, O. Maschi, G. V. Galli, R. Fagnani, E. Dal Cero, D. Caruso and E. Bosisio, Inhibition of platelet aggregation by olive oil phenols via cAMP-phosphodiesterase, Br. J. Nutr. 99 (2008) 945-951; https://doi.org/10.1017/S0007114507837470

32. J. H. Lee and G. H. Kim, Evaluation of antioxidant and inhibitory activities for different subclasses flavonoids on enzymes for rheumatoid arthritis, J. Food Sci. 75 (2010) H212-H217; https://doi. org/10.1111/j.1750-3841.2010.01755.x

33. J. Vibes, B. Lasserre, J. Gleye and C. Declume, Inhibition of thromboxane A2 biosynthesis in vitro by the main components of Crataegus oxyacantha (Hawthorn) flower heads, Prostaglandins Leukot. Essent. Fatty Acids 50 (1994) 173-175; https://doi.org/10.1016/0952-3278(94)90141-4

34. I. Babić, M. Bojić, Ž. Maleš, R. Zadro, K. Gojčeta, I. Duka, H. Rimac and I. Jukić, Influence of flavonoids' lipophilicity on platelet aggregation, Acta Pharm. 69 (2019) (this issue).

35. M. L. Liang, X. W. Da, A. D. He, G. Q. Yao, W. Xie, G. Liu, J. Z. Xiang and Z. Y. Ming, Pentamethylquercetin (PMQ) reduces thrombus formation by inhibiting platelet function, Sci. Rep. 5 (2015) 11142 (11 pages); https://doi.org/10.1038/srep11142

36. Ž. Maleš, A. Antolić, I. Babić, S. Jurić and M. Bojić, Quantitative analysis of phenolic acids and antiplatelet activity of Melissa officinalis leaf extracts, Nat. Prod. Commun. 12 (2017) 93-94; https://doi. org/10.1177/1934578X1701200126

37. O. Estrada, W. Contreras, G. Acha, E. Lucena, W. Venturini, A. Cardozo and C. Alvarado-Castillo, Chemical constituents from Licania cruegeriana and their cardiovascular and antiplatelet effects, Molecules 19 (2014) 21215-21225; https://doi.org/10.3390/molecules191221215

38. R. Kasimu, Z. Fan, X. Wang, J. Hu, P. Wang and J. Wang, Anti-platelet aggregation activities of different fractions in leaves of Apocynum venetum L., J. Ethnopharmacol. 168 (2015) 116-121; https://doi. org/10.1016/j.jep.2015.03.013 0378-8741

39. J. Y. Ro, J. H. Ryu, H. J. Park and H. J. Cho, Onion (Allium cepa L.) peel extract has anti-platelet effects in rat platelets, Springerplus 4 (2015) 17 (8 pages); https://doi.org/10.1186/s40064-015-0786-0

40. A. Antolić, Ž. Maleš, M. Tomičić and M. Bojić, The effect of short-toothed and Dalmatian sage extracts on platelet aggregation, Food Technol. Biotech. 56 (2018) 265-269; https://doi.org/10.17113/ ftb.56.02.18.5474

41. A. D. Assefa, E. Y. Ko, S. H. Moon and Y. S. Keum, Antioxidant and antiplatelet activities of flavonoid-rich fractions of three citrus fruits from Korea, 3 Biotech. 6 (2016) 109 (10 pages); https://doi. org/10.1007/s13205-016-0424-8

42. M. Bojić, A. Antolić, M. Tomičić, Ž. Debeljak and Ž. Maleš, Propolis ethanolic extracts reduce adenosine diphosphate induced platelet aggregation determined on whole blood, Nutr. J. 17 (2018) 52 (8 pages); https://doi.org/10.1186/s12937-018-0361-y

43. C. H. Lescano, F. Freitas de Lima, C. B. Mendes-Silvério, A. F. O. Justo, D. da Silva Baldivia, C. P. Vieira, E. J. Sanjinez-Argandoña, C. A. L. Cardoso, F. Z. Mónica and I. Pires de Oliveira, Effect of polyphenols from Campomanesia adamantium on platelet aggregation and inhibition of cyclooxygenases: Molecular docking and in vitro analysis, Front. Pharmacol. 9 (2018) 617 (13 pages); https://doi. org/10.3389/fphar.2018.00617

44. A. Mira, W. Alkhiary and K. Shimizu, Antiplatelet and anticoagulant activities of Angelica shikokiana extract and its isolated compounds, Clin. Appl. Thromb. Hemost. 23 (2017) 91-99; https://doi. org/10.1177/1076029615595879

45. A. A. Boligon, V. C. Pimentel, M. D. Bagatini and M. L. Athayde, Effect of Scutia buxifolia Reissek in nucleotidase activities and inhibition of platelet aggregation, J. Nat. Med. 69 (2015) 46-54; https://doi. org/10.1007/s11418-014-0858-4

46. S. U. Kwon, H. Y. Lee, M. Xin, S. J. Ji, H. K. Cho, D. S. Kim, D. K. Kim and Y. M. Lee, Antithrombotic activity of Vitis labrusca extract on rat platelet aggregation, Blood Coagul. Fibrin. 27 (2016) 141-146; https://doi.org/10.1097/MBC.0000000000000394 
47. M. S. Rajput, N. Balekar and D. K. Jain, Inhibition of ADP-induced platelet aggregation and involvement of non-cellular blood chemical mediators are responsible for the antithrombotic potential of the fruits of Lagenaria siceraria, Chin. J. Nat. Med. 12 (2014) 599-606; https://doi.org/10.1016/S18755364(14)60091-1

48. J. Rywaniak, B. Luzak, A. Podsedek, D. Dudzinska, M. Rozalski and C. Watala, Comparison of cytotoxic and anti-platelet activities of polyphenolic extracts from Arnica montana flowers and Juglans regia husks, Platelets 26 (2015) 168-176; https://doi.org/10.3109/09537104.2014.894970

49. R. Zamora-Ros, V. Knaze, L. Luján-Barroso, N. Slimani, I. Romieu, V. Fedirko, M. S. Magistris, U. Ericson, P. Amiano, A. Trichopoulou, V. Dilis, A. Naska, D. Engeset, G. Skeie, A. Cassidy, K. Overvad, P. H. M. Peeters, J. M. Huerta, M.-J. Sánchez, J. R. Quirós, C. Sacerdote, S. Grioni, R. Tumino, G. Johansson, I. Johansson, I. Drake, F. L. Crowe, A. Barricarte, R. Kaaks, B. Teucher, H. B. Bueno-deMesquita, C. T. M. Rossum, T. Norat, D. Romaguera, A.-C. Vergnaud, A. Tjønneland, J. Halkjær, F. Clavel-Chapelon, M.-C. Boutron-Ruault, M. Touillaud, S. Salvini, K.-T. Khaw, N. Wareham, H. Boeing, J. Förster, E. Riboli and C. A. González, Estimated dietary intakes of flavonols, flavanones and flavones in the European Prospective Investigation into Cancer and Nutrition (EPIC) 24 hour dietary recall cohort, Br. J. Nutr. 106 (2011) 1915-1925; https://doi.org/10.1017/S000711451100239X

50. P. C. Hollman, J. H. de Vries, S. D. van Leeuwen, M. J. Mengelers and M. B. Katan, Absorption of dietary quercetin glycosides and quercetin in healthy ileostomy volunteers, Am. J. Clin. Nutr. 62 (1995) 1276-1282; https://doi.org/10.1093/ajcn/62.6.1276

51. C. Manach, G. Williamson, C. Morand, A. Scalbert and C. Rémésy, Bioavailability and bioefficacy of polyphenols in humans. I. Review of 97 bioavailability studies, Am. J. Clin. Nutr. 81 (2005) 230S242S; https://doi.org/10.1093/ajcn/81.1.230S

52. K. S. Krogholm, L. Bredsdorff, P. Knuthsen, J. Haraldsdóttir and S. E. Rasmussen, Relative bioavailability of the flavonoids quercetin, hesperetin and naringenin given simultaneously through diet, Eur. J. Clin. Nutr. 64 (2010) 432-435; http://doi.org/10.1038/ejcn.2010.6

53. I. Palomo, A. Concha-Meyer, M. Lutz, M. Said, B. Sáez, A. Vásquez and E. Fuentes, Chemical characterization and antiplatelet potential of bioactive extract from tomato pomace (byproduct of tomato paste), Nutrients 11 (2019) Article ID 456 (10 pages); https://doi.org/10.3390/nu11020456

54. T. Nickel, K. Lackermair, J. Scherr, A. Calatzis, M. Vogeser, H. Hanssen, G. Waidhauser, U. Schönermark, H. Methe, S. Horster, U. Wilbert-Lampen and M. Halle, Influence of high polyphenol beverage on stress-induced platelet activation, J. Nutr. Health Aging 20 (2016) 586-593; https://doi. org/10.1007/s12603-016-0697-y

55. K. Thompson, H. Hosking, W. Pederick, I. Singh and A. B. Santhakumar, The effect of anthocyanin supplementation in modulating platelet function in sedentary population: a randomised, doubleblind, placebo-controlled, cross-over trial, Br. J. Nutr. 118 (2017) 368-374; https://doi.org/10.1017/ S0007114517002124

56. J. J. Peterson, J. T. Dwyer, P. F. Jacques and M. L. McCullough, Do flavonoids reduce cardiovascular disease incidence or mortality in US and European populations? Nutr. Rev. 70 (2012) 491-508; https:// doi.org/10.1111/j.1753-4887.2012.00508.x

57. Z. M. Wang, D. Zhao, Z. L. Nie, H. Zhao, B. Zhou, W. Gao, L. S. Wang and Z. J. Yang, Flavonol intake and stroke risk: a meta-analysis of cohort studies, Nutrition 30 (2014) 518-523; https://doi.org/10.1016/j. nut.2013.10.009 